\title{
Near-neighbor mixing and bond dilation in mechanically alloyed $\mathrm{Cu}-\mathrm{Fe}$
}

\author{
V. G. Harris, K. M. Kemner, B. N. Das, N. C. Koon, and A. E. Ehrlich \\ U.S. Naval Research Laboratory, Washington, D.C. 20375 \\ J. P. Kirkland \\ SFA Inc., Landover, Maryland 20785 \\ J. C. Woicik \\ National Institute of Standards and Technology, Gaithersburg, Maryland 20899 \\ P. Crespo and A. Hernando \\ Instituto de Magnetismo Aplicado, Las Rozas, 28230 Madrid, Spain \\ A. Garcia Escorial \\ Centro Nacional de Investigaciones Metalurgicas-Centro Superior de Investigaciones Cientificas, 28040 Madrid, Spain \\ (Received 5 January 1996; revised manuscript received 4 April 1996)

\begin{abstract}
Extended x-ray-absorption fine-structure (EXAFS) measurements were used to obtain element-specific, structural, and chemical information of the local environments around $\mathrm{Cu}$ and $\mathrm{Fe}$ atoms in high-energy ballmilled $\mathrm{Cu}_{x} \mathrm{Fe}_{1-x}$ samples $(x=0.50$ and 0.70). Analysis of the EXAFS data shows both $\mathrm{Fe}$ and $\mathrm{Cu}$ atoms reside in face-centered-cubic sites where the first coordination sphere consists of a mixture of $\mathrm{Fe}$ and $\mathrm{Cu}$ atoms in a ratio which reflects the as-prepared stoichiometry. The measured bond distances indicate a dilation in the bonds between unlike neighbors which accounts for the lattice expansion measured by x-ray diffraction. These results indicate that metastable alloys having a positive heat of mixing can be prepared via the high-energy ballmilling process. [S0163-1829(96)10033-3]
\end{abstract}

\section{INTRODUCTION}

In recent years there has been renewed interest in extending the mutual solubility of $\mathrm{Fe}$ and $\mathrm{Cu}$. One reason is the observation of giant magnetoresistance in heterogeneous samples which have small ferromagnetic particles coherently suspended within a nonmagnetic noble metal matrix. ${ }^{1,2}$ The easiest way to obtain such a structure in the $\mathrm{Cu}-\mathrm{Fe}$ system is the controlled heat treatment of a solid solution. However, obtaining a solid-solution of $\mathrm{Cu}-\mathrm{Fe}$ is not a trivial matter. The $\mathrm{Cu}-\mathrm{Fe}$ equilibrium phase diagram indicates little or no miscibility of either constituent at room temperature, and only $\approx 4$ at. $\% \mathrm{Fe}$ dissolves into $\mathrm{Cu}$ and $\approx 10$ at. $\% \mathrm{Cu}$ into $\mathrm{Fe}$ near their respective liquidus lines. ${ }^{3}$ However, extended regions of metastable solubility can be obtained via vaporquenching techniques. ${ }^{4,5}$ Recently, an alternative path to vapor-quenching, high-energy ball-milling (HEBM), has been proposed to form solid solutions of combinations of elements having a positive heat of mixing.

HEBM is a process which utilizes the energy of ballistic collisions between particles of a charge material and the surface of hardened steel balls and/or the walls of a shaking container to mix, fragment, and ultimately amorphize or dissolve the charge materials. HEBM has become a popular technique in recent years for the solid-state amorphization of binary metal systems, ${ }^{6,7}$ metal-metalloid systems, ${ }^{8-10}$ and even single-component systems. ${ }^{11}$ Thermodynamic and kinetic models which explain these processes have been proposed. ${ }^{12-15}$ It had been widely held that a negative heat of mixing was required in order to experience single-phase, atomic mixing (i.e., alloying) in the HEBM binary metal systems. However, recently HEBM has been reported to form metastable alloys, or more correctly supersaturated solid solutions, of combinations of elements which do not exhibit appreciable solubility in their equilibrium phase diagrams. ${ }^{15-21}$ The alloying phenomenon in these materials has been explained by Yavari, Desre, and Benameur ${ }^{15}$ to arise when small fragments, created by codeformation, obtain a critical tip radii, whereupon capillary forces bring about the dissolution of the tip region. Subsequently, the solute content changes within the local spinode increasing the critical radius causing the more rapid dissolution of the region and the eventual complete mixing of one component into the other.

The reports concerning the formation and characterization of HEBM alloys having a positive heat of mixing have relied largely upon electron microscopy and x-ray-scattering techniques to establish the onset and degree of mixing. However, when crystallites become increasingly strained and reduced in size, as they do in HEBM, diffracted intensities experience a reduction in amplitude from Debye-Scherrer broadening, leading to the smearing of the diffraction features often beyond visual detection. These effects may lead to a misinterpretation of these data and consequently a misunderstanding of the physical state of the sample.

In order to investigate if alloying occurs in HEBM samples having a positive heat of mixing, we have used $\mathrm{x}$-ray diffraction in combination with extended x-rayabsorption fine-structure (EXAFS) measurements to study both the long-range and the short-range structure and chemistry in $\mathrm{HEBM} \mathrm{Cu}_{x} \mathrm{Fe}_{1-x}(x=0.5$ and 0.7$)$ samples. These compositions are well outside the miscibility regions in the $\mathrm{Cu}-\mathrm{Fe}$ equilibrium phase diagram and are not expected to form solid solutions under steady-state conditions. 
The magnetic and structural properties of HEBM $\mathrm{Cu}-\mathrm{Fe}$ samples, including those having the same compositions as studied here, have been reported previously by others. ${ }^{15,22-26}$ In those studies, the degree of chemical and structural shortrange order was indirectly measured using magnetic measurements, x-ray diffraction, and/or thermal analysis. In an earlier study, Harris et al. employed EXAFS to study HEBM $\mathrm{Cu}_{70} \mathrm{Fe}_{30}, \mathrm{Ag}_{70} \mathrm{Co}_{30}$, and $\mathrm{Ag}_{70} \mathrm{Fe}_{30}$ samples and found via EXAFS near-neighbor modeling analysis that atomic-level mixing had occurred in the $\mathrm{Cu}_{70} \mathrm{Fe}_{30}$ sample which had been milled for $20 \mathrm{~h}$, but not in the Ag-based samples, even after $200 \mathrm{~h}$ of milling. ${ }^{19}$ Crespo et al. ${ }^{20}$ reported the results of EXAFS measurements on HEBM $\mathrm{Cu}_{50} \mathrm{Fe}_{50}$ samples that indicated the nearest-neighbor coordination sphere did indeed reflect a mixed chemistry very near to the nominal values of the starting materials indicating the existence of a supersaturated solid solution. Recently, Schilling et al. ${ }^{21}$ used EXAFS to study the local environments of ball-milled $\mathrm{Cu}_{50} \mathrm{Fe}_{50}$ and $\mathrm{Ag}_{50} \mathrm{Fe}_{50}$ samples and similarly found that the $\mathrm{Cu}_{50} \mathrm{Fe}_{50}$ samples alloyed, while the $\mathrm{Ag}_{50} \mathrm{Fe}_{50}$ samples did not.

In this work we provide direct structural evidence that both the $\mathrm{Fe}$ and $\mathrm{Cu}$ atoms reside in the fcc lattice with a near-neighbor chemistry very near the nominal stoichiometry of the starting materials. These results establish the absence of fcc or bcc single-element clusters, coherent or incoherent, within these samples and indicate that atomic-level mixing has indeed taken place via the HEBM process. In addition, a dilation of the bonds between unlike neighbors was measured via EXAFS which accounts for the expansion of the lattice observed in x-ray-diffraction measurements. This dilation is unique to the unlike atom pairs and is not observed in the bonds between like atom pairs.

\section{MISCIBILITY, ELECTRONIC, AND MAGNETIC PROPERTIES OF Cu-Fe}

\section{A. Miscibility}

The $\mathrm{Cu}-\mathrm{Fe}$ equilibrium phase diagram indicates limited solubility of each element into the other. The solubility of $\mathrm{Fe}$ into $\mathrm{Cu}$ is about $\approx 4$ at. \% at the melting point $\left(1094^{\circ} \mathrm{C}\right)$ and decreases to 0.1 at. $\%$ at $600{ }^{\circ} \mathrm{C}$, and to even smaller amounts near room temperature, while the solubility of $\mathrm{Cu}$ into $\mathrm{Fe}$ is a maximum $\approx 10$ at. $\%$ at $1477{ }^{\circ} \mathrm{C}$ and remains constants at $\approx 0.5$ at. $\%$ near room temperature. ${ }^{3}$ Studying dilute solid solutions, researchers found each element to expand the lattice of the other. ${ }^{27}$ However, several research groups have explored a variety of rapid-quenching techniques which extend the room-temperature miscibility regions by forming metastable alloy concentrations.

The first experimental work on extending the miscibility of the $\mathrm{Cu}-\mathrm{Fe}$ system was performed on bulk solid samples rapidly quenched from elevated temperatures. ${ }^{28,29}$ These studies were successful in stabilizing up to 15 at. $\%$ of $\mathrm{Cu}$ in the bcc Fe matrix. The measured lattice parameters of these alloys were shown to increase near linearly with $\mathrm{Cu}$ content following Vegard's law. Anneals at $573-873 \mathrm{~K}$ were reported to facilitate the decomposition of the alloys to nearly pure bcc $\mathrm{Fe}$ and fcc $\mathrm{Cu}$ components.

Using liquid quenching, Klement further extended the miscibility of $\mathrm{Cu}$ into bcc $\mathrm{Fe}$ to 17.5 at. $\%$ and $\mathrm{Fe}$ in $\mathrm{fcc} \mathrm{Cu}$ to 20 at. $\%{ }^{30}$ These authors found compositions between these two limits to exist as heterogeneous mixtures of bcc and fcc phases. With the development of vapor-quenching techniques the miscibility regions were significantly extended. Kneller, ${ }^{31}$ using thermal evaporation, found $\mathrm{Fe}-\mathrm{Cu}$ alloys having up to 50 at. \% $\mathrm{Cu}$ to have a bcc structure, while alloys with more than 70 at. \%, $\mathrm{Cu}$ could be stabilized in the fcc structure. Once again, intermediate compositions were reported to consist of mixtures of the two phases. Sumiyama, Yoshitake, and Nakmura, ${ }^{4}$ using if sputter deposition, further extended the miscibility of $\mathrm{Cu}$ in bcc $\mathrm{Fe}$ and $\mathrm{Fe}$ in fcc $\mathrm{Cu}$ to nearly 45 at. \% of each. The extended miscibility experienced in sputter deposition over that of thermal evaporation is presumably do to a higher effective quench rate obtained in the high-energy sputtering techniques. Chien et al. ${ }^{5}$ reported on the magnetic and structural properties of a wide range of $\mathrm{Cu}_{1-x} \mathrm{Fe}_{x}$ alloys processed via dc magnetron sputter deposition. They were able to extend the fcc miscibility region up to 72 at. $\% \mathrm{Fe}$ and the bcc miscibility region up to 38 at. $\% \mathrm{Cu}$.

In the past few years, much research has been performed on $\mathrm{Fe}-\mathrm{Cu}$ alloys prepared via HEBM since it was shown that the miscibility of $\mathrm{Fe}$ in $\mathrm{fcc} \mathrm{Cu}$ can be extended to $\approx 60$ at. $\% .^{15,25,26,32,33}$ This technique offers an alternative to rapidquenching techniques to form metastable alloys of elements which are immiscible under equilibrium conditions. Uenishi et al. ${ }^{18}$ report that the lattice parameter of bcc and fcc HEBM $\mathrm{Cu}-\mathrm{Fe}$ alloys increase near linearly with increasing concentration of the dilute element, i.e., $\mathrm{Cu}$ in bcc $\mathrm{Fe}$ and $\mathrm{Fe}$ in fcc $\mathrm{Cu}$, reaching a maximum for $\mathrm{Cu}_{50} \mathrm{Fe}_{50}$. By comparing the lattice parameters measured in HEBM powders to those measured in liquid-quenched ribbons and vapor-quenched thin films, Uenishi et al. ${ }^{18}$ show the volume expansion is significantly larger in HEBM samples. From this it is clear that the HEBM samples have a local structure which must differ from those alloys produced by quenching techniques. It is likely that the difference in lattice parameter between the HEBM samples and those produced via vapor quenching is the result of the total strain energy of the system which varies with the processing technique.

\section{B. Electronic and magnetic properties}

The electronic structure of the $\mathrm{Fe}$ atom has the Ar core with a $3 d^{6} 4 s^{2}$ valence. However, when $\mathrm{Fe}$ is combined with other $\mathrm{Fe}$ atoms to form a metal, some of the lower level electrons are promoted. In the case of $\mathrm{Fe}$, the $3 d$ majority band becomes nearly filled, 4.8 of 5 states, and the minority band has 2.6 of 5 states filled. The two $4 s$ states each have 0.3 occupancy. This configuration provides the $2.2 \mu_{B}$ measured in bcc Fe. In addition, it is the strong $3 d$ $3 d$ interactions and their directionality constraints which dictate the bcc structure. Alternatively, the $\mathrm{Cu}$ atom has the $\mathrm{Ar}$ core with a $3 d^{10} 4 s^{1}$ valence. In its metallic state both $3 d$ bands are filled and the two $4 s$ states are each half occupied. ${ }^{27}$ With both $3 d$ bands filled, the $\mathrm{Cu}$ atom carries no magnetic moment. The strong interaction between $\mathrm{Cu}$ atoms in metallic $\mathrm{Cu}$ derive from the $4 s$ (and some degree of $4 p$ ) hybridization. ${ }^{34}$

When $\mathrm{Cu}$ is alloyed with $\mathrm{Ni}\left(\mathrm{Ar}\right.$ core $\left.+3 d^{8} 4 s^{2}\right)$, the measured $\mu_{B}$ per Ni atom shows a linear decrease with increasing $\mathrm{Cu}$ content. It was once believed that the addition of each $\mathrm{Cu}$ atom was equivalent to adding one electron to the alloy 
which would then occupy the lowest energy state of the alloy which is in the $3 d$ minority band of $\mathrm{Ni}^{27}$ When $\approx 60 \%$ of the atoms are $\mathrm{Cu}$ the net magnetization of the alloy becomes zero at $0 \mathrm{~K}^{35}$ However, more recent experimental ${ }^{36,37}$ and theoretical ${ }^{38}$ studies show the local $3 d$ holes do not completely fill with the addition of $\mathrm{Cu}$. Hence, the diminution of the magnetic moment may result from the depopulation of the majority band concurrent with the population of the minority band. In contrast, when $\mathrm{Cu}$ is alloyed with $\mathrm{Fe}$, the magnetic moment per Fe atom does not change appreciably even at high $\mathrm{Cu}$ concentrations. ${ }^{4,5,26}$ The magnetic moment behavior is characteristic of magnetic dilution, where the sample's saturation magnetization decreases linearly with increasing $\mathrm{Cu}$ but the $\mu_{B} / \mathrm{Fe}$ atom remains constant until the percolation limit is reached. The reason for this is that the high-density Fe $d$ states are poorly matched in energy with the low-density $\mathrm{Cu} s$ states and little hybridization takes place. ${ }^{39}$ As a result, the addition of $\mathrm{Cu}$ does not strongly influence the electronic structure of Fe near the Fermi surface and does not significantly disturb the magnetism of $\mathrm{Fe}$. Additional evidence is the observation that the introduction of $\mathrm{Cu}$ does not force the $\mathrm{Fe}$ to strong ferromagnetism, which is defined by the filled majority spin band, until very high concentrations of $\mathrm{Cu}$ are present. ${ }^{5}$

Several authors have reported on the magnetic properties of HEBM Cu-Fe samples. Uenishi et al. ${ }^{26}$ in agreement with the thin film work of Chien et al., ${ }^{5}$ have shown that the moment per Fe atom is near $2.2 \mu_{B}$ for samples having Fe content greater than 50 at. \%, but falls to zero for less than 20 at. \% (i.e., at the onset of the percolation limit). Yavari, Desre, and Benameur ${ }^{15}$ show a nearly equal magnetic moment at room temperature for the HEBM fcc $\mathrm{Cu}_{50} \mathrm{Fe}_{50}$ phase and the equivalent decomposed state (i.e., a mixture of bcc $\mathrm{Fe}$ and $\mathrm{fcc} \mathrm{Cu}$ ).

These results qualitatively differ with the theoretical work of Fu and Freeman who investigated the electronic and magnetic properties of fcc Fe thin films in intimate contact with fcc $\mathrm{Cu}^{40}$ Although there are, of course, great differences between $\mathrm{Fe}-\mathrm{Cu}$ alloys and thin $\mathrm{Fe} / \mathrm{Cu}$ layers which limit the extent of comparison, some insight can be gained by studying the electronic interactions at the $\mathrm{Fe}-\mathrm{Cu}$ interface. Specifically, $\mathrm{Fu}$ and Freeman, using the full-potential, linearized-augmented-plane-wave ${ }^{41}$ approach to calculating electronic structure, found that the $\mathrm{Fe}-\mathrm{Cu}$ interlayer distance was contracted by $3 \%$ relative to the $\mathrm{Cu}-\mathrm{Cu}$ distance, i.e., from 1.805 to $1.75 \AA$. They also report an enhanced calculated magnetic moment on the $\mathrm{Fe}$ atom of $2.85 \mu_{B}$ when $\mathrm{Fe}$ is in intimate contact with $\mathrm{Cu}$. These results may be a consequence of having an fcc Fe lattice parameter near that of $\mathrm{Cu}$, whereas the $\mathrm{Fe}-\mathrm{Cu}$ alloys studied here and others made by vapor quenching have lattice parameters significantly larger.

\section{EXPERIMENTAL}

\section{A. Materials processing}

The samples in this study were processed using a Spex ${ }^{\mathrm{TM}}$ (Ref. 42) mill with elemental starting materials having 99.99\% purity or better. The $\mathrm{Cu}_{70} \mathrm{Fe}_{30}$ samples were processed at the Naval Research Laboratory (Washington, D.C.) by milling elemental powders of $\mathrm{Fe}$ and $\mathrm{Cu}$ for a period of $20 \mathrm{~h}$ with two $8 \mathrm{~g}$ steel balls having radii of $\approx 6 \mathrm{~mm}$ and two smaller $1 \mathrm{~g}$ balls having radii of $\approx 3 \mathrm{~mm}$. The $\mathrm{Cu}_{50} \mathrm{Fe}_{50}$ samples were produced at the Instituto de Magnetismo Aplicado (Madrid, Spain) using a Fritsch ${ }^{\mathrm{TM}}$ (Ref. 42) vibrating mill and starting materials of high-purity $\mathrm{Fe}$ powder and $\mathrm{Cu}$ foil. Milling was performed using a single $6 \mathrm{~cm}$ steel ball for a period of 400 h. $^{20,25}$ For both milling operations the elemental starting materials were carefully weighed and introduced into the mill which was then capped under an argongas environment to limit the amount of oxidation during milling.

\section{B. Extended x-ray-absorption fine structure}

The x-ray-absorption coefficients encompassing the $\mathrm{Fe}$ and $\mathrm{Cu} K$ absorption edges were collected using the X23B and X23A2 beamlines at the National Synchrotron Light Source (Brookhaven National Laboratories, Upton, New York). Both beamlines, X23B and X23A2, were designed for but not limited to EXAFS measurements. They both employ double-crystal, fixed-exit monochromators with beamline X23B using a pair of Si (111) crystals and X23A2 using a pair of Si (311) crystals. The EXAFS data were collected when the storage ring energy was $2.5 \mathrm{GeV}$ with a current between 110 and $250 \mathrm{~mA}$.

Because of strain hardening caused by the milling procedure, it was difficult to grind the powders to a suitable particle size for use with the EXAFS transmission data collection technique. Hence, we opted to use the total-electronyield (TEY) data collection technique where we applied a generous amount of the powder over a still-wet coating of colloidal graphite on a substrate of commercial grade Al foil to construct the TEY sample. In TEY data collection the sample is used as the cathode in a He gas-flow ionization cell where the $\mathrm{x}$-ray absorption is monitored by measuring the sample current induced by the by products of the core hole decay, namely the Auger and secondary electrons.

EXAFS data were collected from the milled powders and thin foils of $\mathrm{Fe}$ and $\mathrm{Cu}$. The later data were collected in the transmission mode and used as empirical standards of the bcc and fcc structure, respectively. Prior to data collection, the detector circuit linearity was measured by comparing the ratio of the transmitted signal $\left(I_{t}\right)$, or in the case of TEY the sample current $\left(I_{s}\right)$, to the incident signal $\left(I_{0}\right)$, above the $\mathrm{Fe}$ and $\mathrm{Cu}$ absorption edges before and after the beam was attenuated $50 \%$. The incident beam was attenuated by placing several layers of 0.01 in. commercial grade $\mathrm{Al}$ foil upstream of the sample and detectors. The linearity of the detector circuit was found to vary less than $0.5 \%$ indicating suitable conditions for data collection.

Following established EXAFS analysis procedures, ${ }^{43}$ a line was fit to the preabsorption edge region and the area under this line and its extrapolation were removed from the spectrum. The extended fine structure appearing from 20$800 \mathrm{eV}$ above the absorption edge were isolated and normalized to the edge step height and energy, thus putting all data on a per atom basis. Residual, nonoscillatory curvature in the data was eliminated by fitting and removing a cubic spline curve using three equidistant internal knots. These data were then converted to photoelectron wave-vector $(k)$ space and Fourier transformed to radial coordinates $(r)$.

The Fourier transform of the EXAFS data is similar in many respects to a partial radial distribution function (PRDF) obtained by the refinement of x-ray-scattering data. 
The amplitudes of the peaks are typically proportional to the occupation and atomic disorder of the neighboring atom shells, and the radial distances of the peaks correspond to the bond distances between the central absorbing atom and its local neighbors. ${ }^{43}$ The data in this form differ from a PRDF in that corrections for electron phase shifts have not yet been added, hence the radial distances of the Fourier peaks are offset from their true bond distances to lower $r$ values. Notwithstanding, comparison between Fourier-transformed data and similarly analyzed data from empirical standards are useful in determining relative changes in the local structure and atom symmetry.

\section{EXAFS near-neighbor modeling using FEFF}

Theoretical EXAFS data, generated using the FEFF (version 3.11) codes of Rehr et al., ${ }^{44}$ were analyzed in a manner similar to that discussed above. (Henceforth, these data will be referred to as FEFF data.) These data were used to fit Fourier-filtered (FF) $\mathrm{Fe}$ and $\mathrm{Cu}$ EXAFS data from the nearest-neighbor Fourier peak region $(1 \AA \leqslant r \leqslant 3 \AA)$ of the milled samples. The fitting was performed in $k$ space where the phase and amplitude of the oscillations are fit with parametrized FEFF data to determine the local atomic parameters around the absorbing atoms, i.e., bond distances $(r)$, coordination numbers $(\mathrm{CN})$, and the EXAFS Debye-Waller coefficients $\left(\sigma^{2}\right)$. The latter is a measure of both the static and thermal displacement of atoms about a mean bond distance.

Quantitative information of the local structure and chemistry around the $\mathrm{Fe}$ and $\mathrm{Cu}$ sites was obtained by fitting the nearest-neighbor peak region of the Fourier-transformed $\mathrm{Fe}$ and $\mathrm{Cu}$ EXAFS data with FEFF data. In performing this fitting analysis, a data range in $r$ space that encompassed the nearest-neighbor peak $(1 \AA \leqslant r \leqslant 3 \AA$ ) was selected and backFourier transformed (i.e., Fourier-filtered) to $k$ space. In $k$ space, the phase and amplitude of the nearest-neighbor FF EXAFS data were fit using the parametrized FEFF data. The quality of the fit was judged by a least-squares fitting parameter $\left(\chi^{2}\right)$. During the fitting analysis of both the $\mathrm{Cu}$ and $\mathrm{Fe}$ standards, and the data collected from the milled samples, the $r$ of contributing atom shells were floated while all other parameters were fixed at their theoretical values. Once approximate values of the radial distances were determined, additional fits were carried out in which the $r$ values were fixed and the $\mathrm{CN}$ and $\sigma^{2}$ values were allowed to vary. Further refinement of the fit was achieved by fixing the $\mathrm{CN}$ and $\sigma^{2}$ values at the fitted values and again varying $r$ using the previously determined values as the starting values. Finally, all parameters were floated from the starting values determined from the above approach until a best fit for all parameters was obtained. At no time was the number of fitting parameters greater than the maximum number allowed by the Nyquist theorem, i.e., $(2 \Delta k \Delta r) / \pi \cdot{ }^{45}$ The best fits for the $\mathrm{Cu}$ and $\mathrm{Fe}$ standards were further refined by systematically varying the edge energy correction, $v_{0}$, and the amplitude reduction coefficient, $S_{0}^{2}$, until the $\chi^{2}$ fitting parameter was optimized.

\section{RESULTS AND DISCUSSIONS}

\section{A. X-ray-diffraction measurements}

$\mathrm{X}$-ray-diffraction measurements of the milled powders were performed using a Philips ${ }^{\mathrm{TM}}$ (Ref. 42) diffractometer

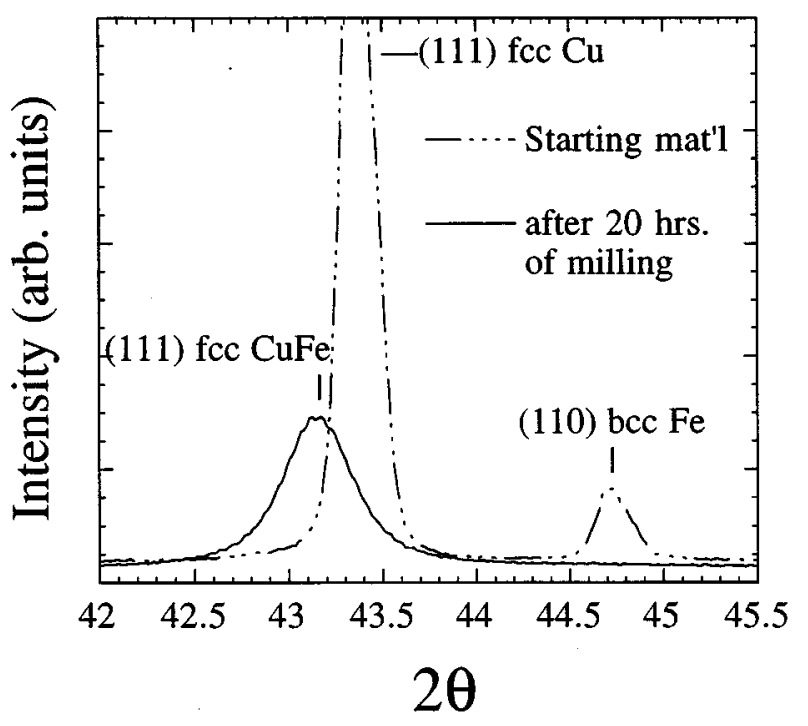

FIG. 1. A portion of the $\theta-2 \theta$ x-ray-diffraction scan of the $\mathrm{Cu}_{70} \mathrm{Fe}_{30}$ material before and after HEBM illustrating the disappearance of the (110) bcc Fe peak and the shift of the (111) fcc Cu peak to a higher $d$ spacing.

equipped with a fixed anode, $\mathrm{Cu} K \alpha$ source. Figure 1 is a plot of a portion of the $\theta-2 \theta$ scan for the $\mathrm{Cu}_{70} \mathrm{Fe}_{30}$ sample before and after milling. The asymmetry of the $\mathrm{Fe}(110)$ peak in the scan of the starting materials is caused by the unfiltered $K \alpha_{2}$ radiation having $\lambda=1.544 \AA$. These data are representative of both milled samples with slight differences corresponding to the change in the lattice parameter between the two samples. In Fig. 1 it is clear that after $20 \mathrm{~h}$ of milling, the bcc(110) peak of $\mathrm{Fe}$ has completely disappeared and that the fcc(111) peak of $\mathrm{Cu}$ has significantly shifted to a higher $d$ spacing. This signals that the Fe atoms now exist in the fcc phase. The absence of a second family of fcc peaks suggests that the $\mathrm{Fe}$ and $\mathrm{Cu}$ atoms coexist in a single fcc phase. Lattice parameters of $3.641 \pm 0.005 \AA$ and $3.634 \pm 0.003 \AA$ were calculated for the $\mathrm{Cu}_{50} \mathrm{Fe}_{50}$ and $\mathrm{Cu}_{70} \mathrm{Fe}_{30}$ samples, respectively. These values are significantly greater than the values predicted by Vegard's law, $3.6025 \AA$ for $\mathrm{Cu}_{50} \mathrm{Fe}_{50}$ and $3.6075 \AA$ for $\mathrm{Cu}_{70} \mathrm{Fe}_{30}$, representing an expansion of $3.24 \%$ and $2.22 \%$ in volume, respectively. The expansion in the lattice constant of the HEBM Cu-Fe samples has been shown to increase with both increased milling time and increased $\mathrm{Fe}$ concentration peaking near 50 at. \%, suggesting that the expansion is due to the progressive incorporation of $\mathrm{Fe}$ into the $\mathrm{Cu}$ lattice. ${ }^{15}$ The lattice parameters measured here are comparable to those measured by Uenishi et al. for HEBM $\mathrm{Cu}-\mathrm{Fe}$ samples. ${ }^{26}$ Similar to the values of Uenishi et al., these are larger than those measured for vapor-quenched ${ }^{4,5}$ and liquid-quenched samples. ${ }^{46}$ It is likely that the difference between the values for HEBM samples and those processed using liquid- and vapor-quenching techniques is due to the total strain energy in the lattice introduced by the processing technique.

The lattice expansion induced by the introduction of the $\mathrm{Fe}$ atoms to the $\mathrm{Cu}$ matrix via HEBM suggests that within this environment the atomic radii of the $\mathrm{Fe}$ and/or $\mathrm{Cu}$ atoms are different compared with those of their pure phase states. It is well known that the average atomic radius of an element can change considerably depending upon the environment in 


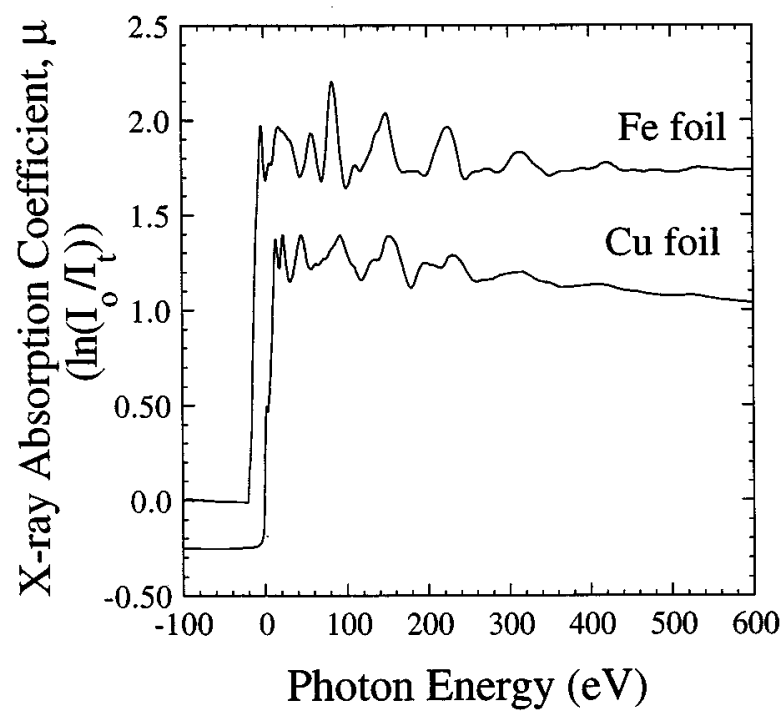

FIG. 2. X-ray-absorption coefficient [as the $\ln \left(I_{t} / I_{0}\right)$ where $I_{t}=$ transmitted signal, $I_{0}=$ incident signal $]$ encompassing the $\mathrm{Fe}$ and $\mathrm{Cu} K$ absorption edges in $\mathrm{Fe}$ and $\mathrm{Cu}$ foils, respectively. The $\mathrm{Cu}$ data have been shifted in energy and vertically offset to avoid overlapping the Fe data.

which it is placed. Typically, these changes are determined by measurements made via $\mathrm{x}$-ray diffraction (XRD) where small changes in the unit cell dimensions can be measured with great accuracy. Using this approach, one obtains a measure of the average local distortion to the lattice caused by the introduction of one element into another, but it is unclear which element changes size. By applying EXAFS, an element-specific local probe, one should be able to discern if the lattice expansion is the result of an isotropic dilation of all bonds or if it is due to a specific atom pair correlation.

These XRD results suggest that the HEBM $\mathrm{Cu}-\mathrm{Fe}$ samples exist as a single fcc phase. They do not provide information concerning the local chemical homogeneity of the samples and therefore it remains possible that small fcc $\mathrm{Fe}$ clusters have stabilized coherently within the fcc $\mathrm{Cu}$ lattice. ${ }^{47}$ To address this issue we have pursued x-rayabsorption fine-structure studies of these samples which will provide information of the local structure and chemistry around the $\mathrm{Cu}$ and $\mathrm{Fe}$ sites. The results of that study are presented in Sec. IV C.

\section{B. Extended x-ray-absorption fine-structure analysis of fec $\mathrm{Cu}$ and bec Fe standards}

Figure 2 is a plot of the x-ray-absorption coefficients $\left[\mu=\ln \left(I_{0} / I_{t}\right)\right]$ encompassing the $\mathrm{Fe}$ and $\mathrm{Cu} K$ absorption edges collected from the $\mathrm{Fe}$ and $\mathrm{Cu}$ foil standards, respectively. The oscillations appearing above the edges are the fine structure of EXAFS and arise from the modulation of the $\mathrm{x}$-ray-absorption coefficient from the interference of the outgoing and backscattered photoelectron waves caused by absorption. These oscillations contain information on the local environment around the absorbing atoms. The data from the $\mathrm{Fe}$ and $\mathrm{Cu}$ foils are used here as empirical standards of the bcc and fcc structures as well as chemical standards for the modeling of the $\mathrm{Fe}$ and $\mathrm{Cu}$ EXAFS data collected from the milled samples. One sees in comparing the $\mathrm{Fe}$ and $\mathrm{Cu}$ data of Fig. 2 that there are pronounced differences in the

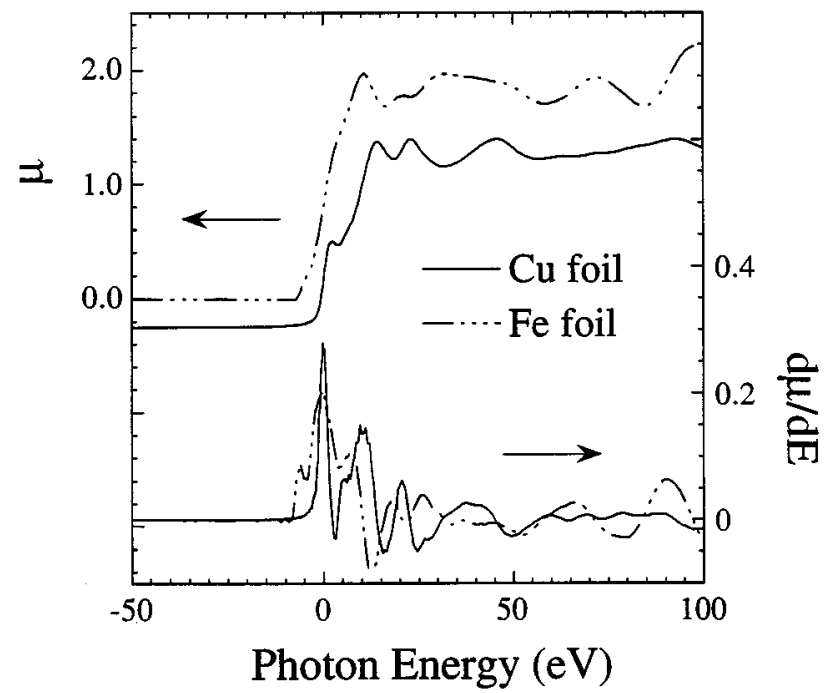

FIG. 3. X-ray-absorption near-edge fine structure (XANES) for the $\mathrm{Fe}$ and $\mathrm{Cu} K$ absorption edges collected from $\mathrm{Fe}$ and $\mathrm{Cu}$ foils, respectively. The Fe data have been vertically offset to allow direct comparisons to the $\mathrm{Cu}$ data. The curves positioned on the lower portion of the figure are derivatives of these same data.

fine structure between these data sets. These differences are most noticeable in the near-edge fine structure including the edge region and extending to $\approx 150 \mathrm{eV}$ above the edge.

Figure 3 illustrates an expanded view $(-50-100 \mathrm{eV})$ of the near-edge region and the derivative of the same. The derivative is supplied to more clearly contrast the differences between data sets in the near-edge region. The structure appearing very near the absorption edge is referred to as the $\mathrm{x}$-ray-absorption near-edge structure, or XANES, and contains information more heavily weighted by the local atom symmetry and the density of states. In this figure, one sees that the $\mathrm{Cu}$ data have a small peak appearing halfway up the absorption edge step which is absent in the Fe data. In addi-

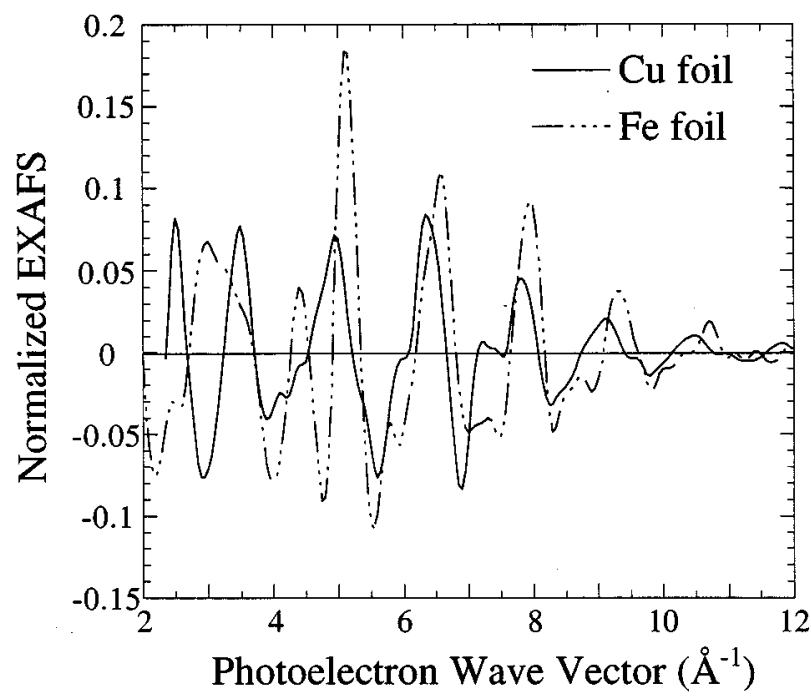

FIG. 4. Normalized EXAFS data after background removal and conversion to photoelectron wave-vector space collected from the $\mathrm{Fe}$ foil (dashed curve) and the $\mathrm{Cu}$ foil (solid curve). Data sets are plotted using the same $x$ and $y$ axes to allow direct comparisons. 
tion, the $\mathrm{Cu}$ data show a pronounced splitting near $20 \mathrm{eV}$ which again is absent from the Fe profile. At higher energies, the oscillations are considerably out of phase with each other indicating differences in atomic symmetry.

After background removal and normalization of the extended fine structure to the edge energy and step height, the data are converted to $k$ space (see Fig. 4). In this form, the EXAFS can be directly compared and contrasted more clearly in terms of their phase and amplitude. The largest differences seen in Fig. 4 are the splitting of the $\mathrm{Cu}$ EXAFS near $3 \AA^{-1}$, which is absent in the Fe, and the splitting of the Fe EXAFS near $5 \AA^{-1}$, which is absent in the $\mathrm{Cu}$. The great differences between $\mathrm{Cu}$ and Fe EXAFS data arise primarily because of the differences in the local atom symmetry in their respective structures. $\mathrm{Cu}$ has a face-centered-cubic (fcc) structure which is a close-packed cubic arrangement of atoms. Because of an incomplete $d$ shell, Fe does not assume a close-packed structure but instead takes a body-centeredcubic (bcc) structure where the atom arrangement satisfies the directionality of the $d$-shell wave functions. Taking a corner atom as our 0th atom $(0,0,0)$, the bcc structure has as

\section{bcc unit cell}
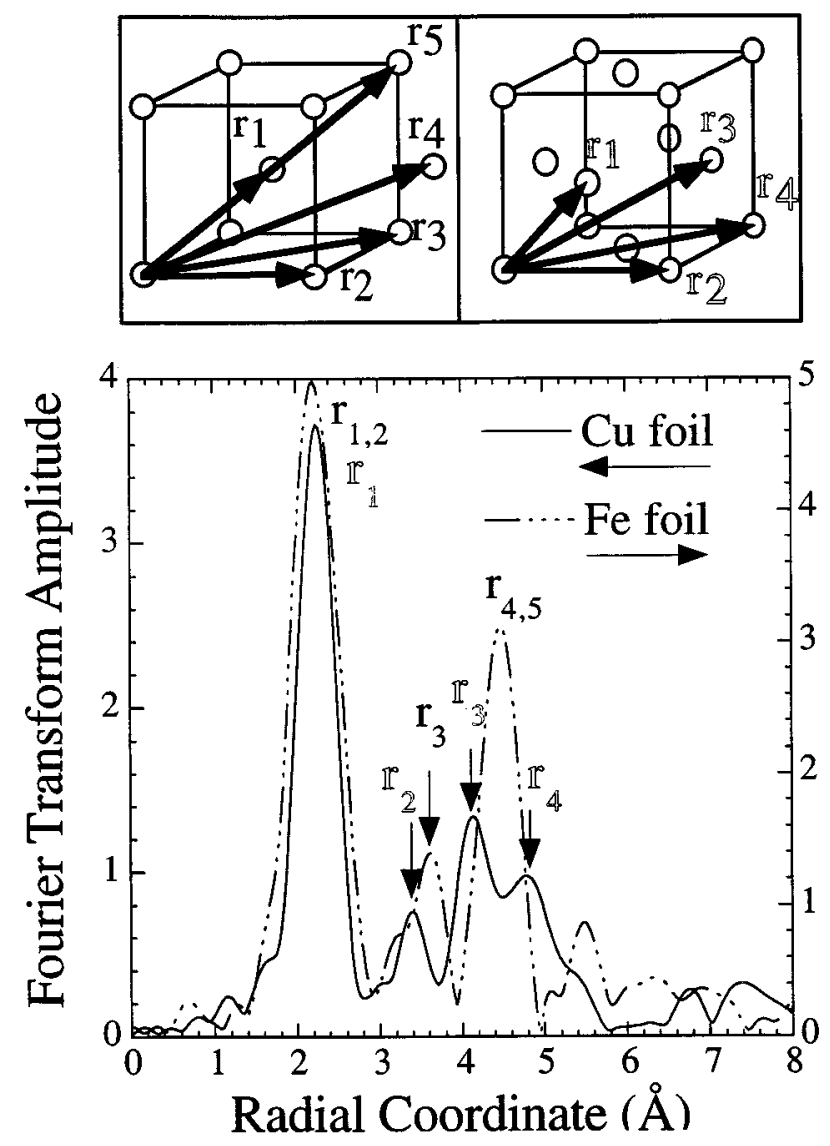

FIG. 5. Fourier-transformed $\mathrm{Cu}$ and Fe EXAFS data collected from $\mathrm{Cu}$ and $\mathrm{Fe}$ foils, respectively. Panels located above the plot depict the bcc and fcc unit cells with vectors from the central atom to the near neighbors. Vectors listed on the plot indicate which atomic pair correlations contribute to the Fourier peaks. All data were transformed using $k^{2}$ weighting and $k$ ranges of $2.5-12.5 \AA^{-1}$. Electron phase shift corrections have not been included in these data, therefore, radial distances do not correspond directly to bond lengths (see text). its nearest-neighbors to the 0th atom the eight body-centered atoms $(1 / 2,1 / 2,1 / 2)$ at a distance of $2.482 \AA$. It's next-nearest neighbors are the six cube edge sites at a distance of $2.866 \AA$ (i.e., the lattice parameter). In contrast, the fcc structure has as its nearest neighbors the 12 face-centered atoms $(1 / 2,1 /$ $2,0)$ at $2.556 \AA$ and next the six cube edge sites at $3.615 \AA$.

Figure 5 is a plot of the Fourier-transformed EXAFS data for the $\mathrm{Cu}$ (solid curve) and Fe (dashed curve) standards. Presented above this plot are depictions of the bcc and fcc unit cells. In each of these panels are $\mathbf{r}$ vectors which originate at the central atom and extend to the near neighbors. These vectors correlate with features in the Fourier profiles presented in the main panel to indicate which atom correlations contribute to the Fourier peaks. Because the Fe EXAFS has a limited $r$-space resolution of $\approx 0.4 \AA$, the first two neighbors of the bcc unit cell contribute to the first Fourier peak in the Fe profile centered near $2.1 \AA$. For this reason, this peak appears much broader than the corresponding peak in the $\mathrm{Cu}$ EXAFS which has 12 nearest neighbors located at a single distance of $2.556 \AA$. Recalling that the Fourier transform of EXAFS data is uncorrected for electron phase shifts, the peaks do not correspond directly to the true bond distances but are instead shifted to lower $r$ values. For example, the $\mathrm{Cu}$ nearest-neighbor peak is seen in Fig. 5 to be centered at $2.125 \AA$ whereas the actual distance is $2.556 \AA$, indicating a phase shift for this correlation of $\approx 0.43 \AA$. The large peak centered near $4.5 \AA$ in the Fourier transform of the bcc Fe EXAFS contains amplitude contributions not only from the $24 \mathbf{r}_{4}$ and eight $\mathbf{r}_{\mathbf{5}}$ neighbors but also from a photoelectron focusing effect caused by the collinear arrangement of the center-body-centered $\left(\mathbf{r}_{1}\right)$-body-diagonal $\left(\mathbf{r}_{5}\right)$ sites. This feature is a useful fingerprint for bcc structures. A similar amplitude enhancement is observed in the fcc $\mathrm{Cu}$ profile near $4.8 \AA$ where the center-face-centered $\left(\mathbf{r}_{1}\right)$-face diagonal $\left(\mathbf{r}_{4}\right)$ sites are arranged collinear with respect to one another.

\section{Extended x-ray-absorption fine-structure analysis of HEBM Cu-Fe samples}

Figure 6 is a plot of the $\mathrm{x}$-ray-absorption as the normal-

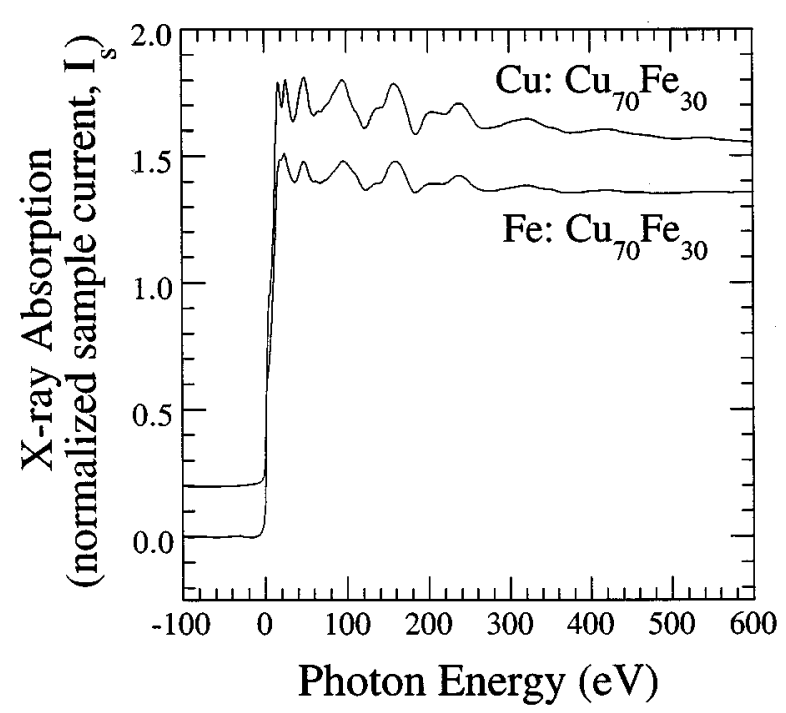

FIG. 6. X-ray-absorption, as normalized sample current $\left(I_{s} / I_{0}\right)$ versus photon energy, for the $\mathrm{Fe}$ and $\mathrm{Cu} K$ absorption edges in the HEBM Cu $\mathrm{Cu}_{70} \mathrm{Fe}_{30}$ sample. The $\mathrm{Cu}$ data have been vertically offset so as not to overlap the Fe data. 


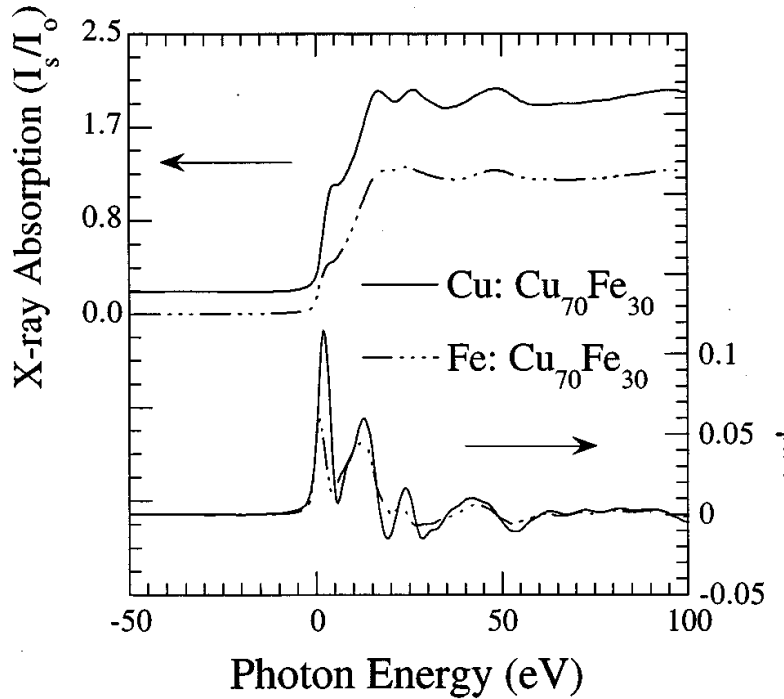

FIG. 7. X-ray-absorption near-edge fine structure (XANES), as normalized sample current $\left[I_{s}(E) / I_{0}(E)\right]$ versus photon energy, for the $\mathrm{Fe}$ and $\mathrm{Cu} K$ absorption edges collected from the HEBM $\mathrm{Cu}_{70} \mathrm{Fe}_{30}$ sample. The $\mathrm{Cu}$ data have been vertically offset so as not to overlap the Fe data. The curves positioned on the lower portion of the figure are derivatives of these same data.

ized sample current $\left(I_{s} / I_{0}\right)$, encompassing the Fe and $\mathrm{Cu} K$ absorption edges collected from the milled $\mathrm{Cu}_{70} \mathrm{Fe}_{30}$ sample. The $\mathrm{Cu}$ data are vertically offset from the Fe data to allow comparison between data sets. These data are qualitatively similar to the $\mathrm{Cu}_{50} \mathrm{Fe}_{50}$ sample. As is readily seen in Fig. 6, the $\mathrm{Cu}$ and $\mathrm{Fe}$ data appear similar. The extended fine structure of both data sets displays oscillations having similar phase and relative amplitudes while the near-edge regions are also similar (see Fig. 7) with some exceptions. In particular, some of the features appearing in the $\mathrm{Cu}$ spectrum appear to be less resolved in the Fe data. Because the energy resolution at the $\mathrm{Fe}$ edge $(7111 \mathrm{eV})$ is slightly better than that of the $\mathrm{Cu}$ edge $(8979 \mathrm{eV})$, this effect cannot be attributable to beamline optics, but instead is likely characteristic of the electronic structure of $\mathrm{Fe}$ in the fcc symmetry. The derivative of the XANES illustrates similarities in the $\mathrm{Fe}$ and $\mathrm{Cu}$ nearedge data, with every feature in the $\mathrm{Cu}$ data represented in the Fe data. From these data one can conclude that both $\mathrm{Fe}$ and $\mathrm{Cu}$ share a similar structure having the same atomic symmetry.

Figure 8 contains the $\mathrm{Fe}$ and $\mathrm{Cu}$ EXAFS from the $\mathrm{Cu}_{70} \mathrm{Fe}_{30}$ sample after normalization and conversion to $k$ space (see Sec. III B). Data collected from a $\mathrm{Cu}$ foil are similarly analyzed and presented as a standard of the fcc structure. In this form, the data can be compared in terms of phase and amplitude of the EXAFS oscillations to determine similarities or differences between samples and also to provide information as to the signal-to-noise characteristics of the experiment. Error bars are presented on both the $\mathrm{Cu}$ and Fe data in Fig. 8 but are difficult to see because of their small size. These error bars represent one standard deviation from the mean calculated by merging five data sets after normalization and conversion to $k$ space. As such, they reflect both the data collection statistics and any uncertainty introduced to the data from the background removal procedures. The very small amplitudes of the error bars illustrate the excellent

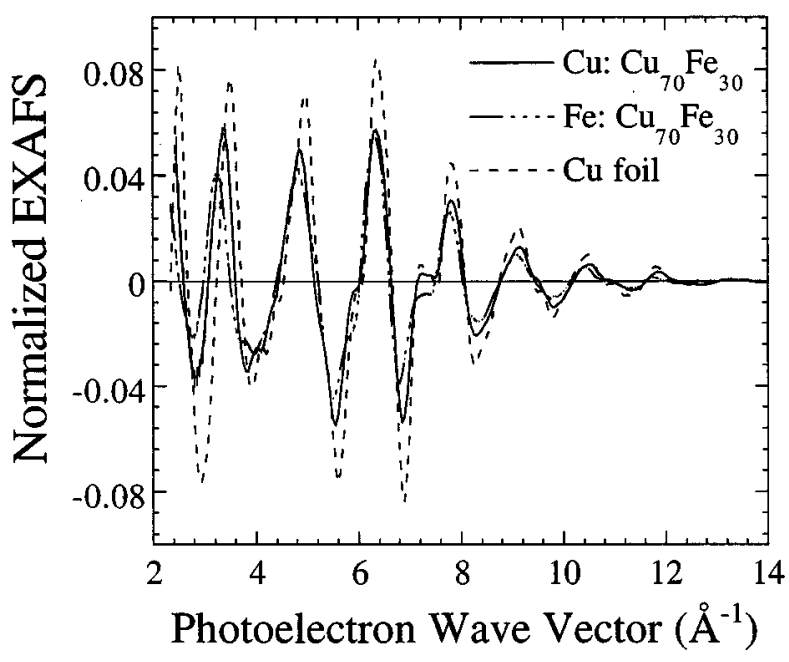

FIG. 8. Normalized EXAFS data after background removal and conversion to photoelectron wave-vector space for Fe (dash-dot-dot curve) and $\mathrm{Cu}$ (solid curve) in the HEBM $\mathrm{Cu}_{70} \mathrm{Fe}_{30}$ sample. Similar data collected from the $\mathrm{Cu}$ foil (dashed curve) is also presented as a standard of the fcc structure. Data sets are plotted using the same $x$ and $y$ axes to allow direct comparisons.

signal-to-noise of the data collection from these samples. Qualitative comparisons between these data, and with the data of the fcc $\mathrm{Cu}$ standard, indicate that both the $\mathrm{Fe}$ and $\mathrm{Cu}$ atoms in the milled samples exist in a close-packed structure similar to that of fcc $\mathrm{Cu}$. Subtle differences between the data sets for the milled sample versus that of the $\mathrm{Cu}$ foil, namely, the reduced amplitude of the oscillations and the slight offset in phase at low $k$ values, can be attributed to the increased structural disorder in the milled samples arising from the impact nature of the HEBM technique and differences in the local chemistry between the standard and milled samples. At this early stage in the analysis, the meaning of these subtle differences is difficult to relate to specific changes in local structure or chemistry. For this reason these data are Fourier transformed to radial coordinates in order to obtain direct information of the structure and atomic symmetry around the absorbing atoms.

The Fourier-transformed EXAFS data from the $\mathrm{Cu}_{50} \mathrm{Fe}_{50}$ sample are presented in Fig. 9. These data are similar to the data collected from the $\mathrm{Cu}_{70} \mathrm{Fe}_{30}$ sample. The $\mathrm{Fe}$ and $\mathrm{Cu}$ EXAFS from the milled sample are presented on the same $x$ and $y$ axes without normalization or offset to allow direct comparisons to be made. The data corresponding to the $\mathrm{Cu}$ standard are presented on the same $x$ axis but different $y$ axis in order to allow an improved comparison between the data from the milled samples and the standard at the higher radial distances (i.e., $r \geqslant 3 \AA$ ). A schematic of the fcc unit cell is presented in the inset panel which indicates which atom correlations contribute to the Fourier peaks. The differences in peak amplitude between the $\mathrm{Cu}$ and Fe EXAFS in the milled samples and the $\mathrm{Cu}$ standard are likely due to an increase in the static displacement component to the EXAFS DebyeWaller coefficient caused by the ballistic nature of the processing and not due to any significant change in the coordination around the absorbing atoms. Data corresponding to the milled samples are shown in Fig. 9 to resemble closely the fcc structure of the $\mathrm{Cu}$ standard in both the relative am- 


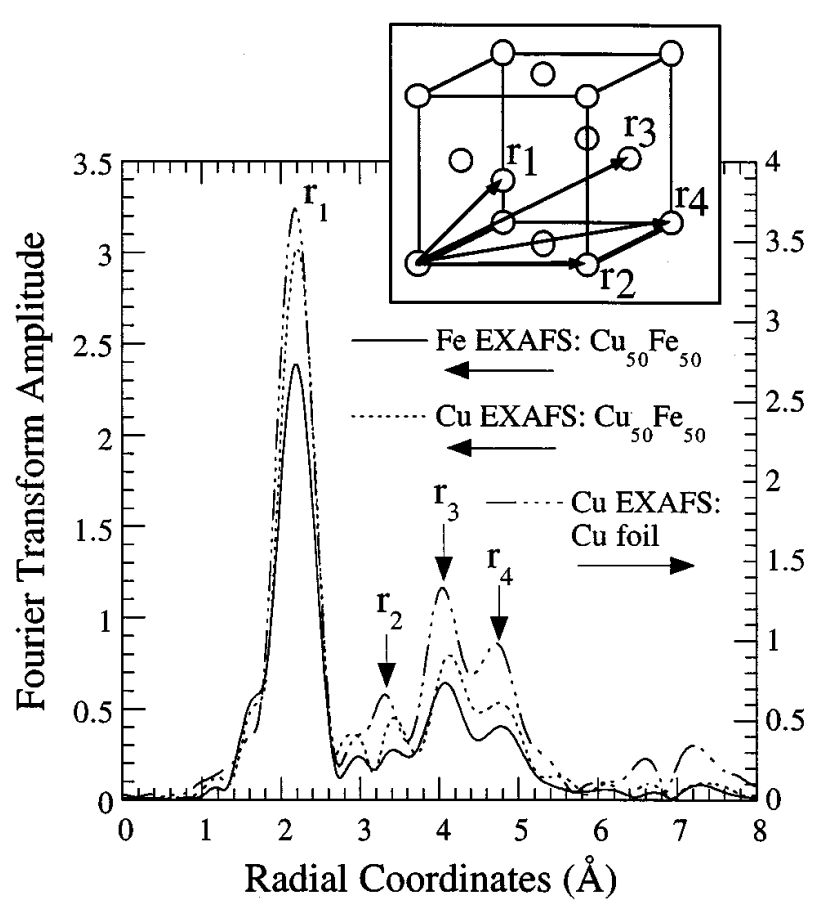

FIG. 9. Fourier-transformed $\mathrm{Fe}$ and $\mathrm{Cu}$ EXAFS data collected from the HEBM $\mathrm{Fe}_{50} \mathrm{Cu}_{50}$ sample with similar data collected from a fcc $\mathrm{Cu}$ standard shown for comparison. All data were transformed using $k^{2}$ weighting and $k$ ranges of $2.5-12.5 \AA^{-1}$. Electron phaseshift corrections have not been included in these data, therefore radial distances do not correspond directly with bond lengths (see text).

plitude and radial distance of Fourier peaks appearing over the $r$ range of 1.5 to $5.5 \AA$. Among the differences between these data are a slight shift of the nearest-neighbor $\left(\mathbf{r}_{1}\right)$ and next-nearest-neighbor $\left(\mathbf{r}_{2}\right)$ peaks; this latter peak corresponds to the lattice parameter. These shifts suggest that the nearestneighbor bond is greater in the milled sample than in the fcc $\mathrm{Cu}$ standard, a result that is consistent with the larger lattice parameter measured in the milled samples using x-ray diffraction. The Fourier-transformed EXAFS data of Fig. 9 establish that both $\mathrm{Fe}$ and $\mathrm{Cu}$ unambiguously reside in fcc structures. It precludes the existence of any significant amount of bcc Fe clusters, which are the more energetically favorable structure for $\mathrm{Fe}$ at room temperature. However, these data do not rule out the possibility that some Fe exists in small fcc clusters, chemically segregated, but structurally coherent, within the fcc $\mathrm{Cu}$ matrix. In order to determine if indeed this is the case, a quantitative study of the nearneighbor environment was undertaken.

\section{Near-neighbor modeling of the extended $x$-ray-absorption fine structure Near-neighbor chemistry}

Quantitative information on the local structure and chemistry around the $\mathrm{Fe}$ and $\mathrm{Cu}$ sites in both the standards and the HEBM samples was obtained by fitting the nearest-neighbor peak region of the Fourier-transformed $\mathrm{Fe}$ and $\mathrm{Cu}$ EXAFS data with FEFF data. The finer details of the fitting methodolgy are presented in Sec. III C. The results of the fitting analysis of the standards and HEBM samples are presented
TABLE I. Structural parameters used to obtain best fits to Fourier-filtered EXAFS data. Note: The error bars listed are derived from comparing the best fits between the mean and mean \pm 1 std. dev. They represent a $25 \%$ increase in the $\chi^{2}$ fitting parameter.

\begin{tabular}{lccc}
\hline \hline \multicolumn{1}{c}{$\begin{array}{c}\text { Pair } \\
\text { correlations }\end{array}$} & $\begin{array}{c}\text { Bond distance } \\
(\AA)\end{array}$ & $\begin{array}{c}\text { Coordination } \\
\text { number }\end{array}$ & $\begin{array}{c}\sigma_{300 \mathrm{~K}}^{2} \\
\left(\AA^{2}\right)\end{array}$ \\
\hline$b c c \mathrm{Fe}\left(S_{0}^{2}=0.85 ; \nu_{0}=-2.5 \mathrm{eV}\right)$ & & \\
$\mathrm{Fe}-\mathrm{Fe}$ & $2.49 \pm 0.005$ & $7.5 \pm 0.2$ & $0.0047 \pm 0.0002$ \\
$\mathrm{Fe}-\mathrm{Fe}$ & $2.84 \pm 0.01$ & $6.5 \pm 0.2$ & $0.0112 \pm 0.0005$ \\
$\mathrm{Theoretical}$ & & & \\
$\mathrm{Fe}-\mathrm{Fe}$ & 2.482 & 6 & \\
$\mathrm{Fe}-\mathrm{Fe}$ & 2.866 & & \\
$f c c \mathrm{Cu}\left(S_{0}^{2}=0.88 ; \nu_{0}=0\right)$ & & & \\
$\mathrm{Cu}-\mathrm{Cu}$ & $2.54 \pm 0.005$ & $12 \pm 0.2$ & $0.0085 \pm 0.0003$ \\
$\mathrm{Theoretical}$ & & & \\
$\mathrm{Cu}-\mathrm{Cu}$ & 2.556 & & \\
$\mathrm{Cu} u_{50} \mathrm{Fe} e_{50}$ & & & \\
$\mathrm{Fe}-\mathrm{Fe}$ & $2.52 \pm 0.005$ & $5.2 \pm 0.3$ & $0.0083 \pm 0.0008$ \\
$\mathrm{Fe}-\mathrm{Cu}$ & $2.63 \pm 0.01$ & $6.3 \pm 0.3$ & $0.0146 \pm 0.0004$ \\
$\mathrm{Cu}-\mathrm{Fe}$ & $2.63 \pm 0.01$ & $4.9 \pm 0.3$ & $0.0121 \pm 0.0005$ \\
$\mathrm{Cu}-\mathrm{Cu}$ & $2.54 \pm 0.005$ & $5.9 \pm 0.3$ & $0.0085 \pm 0.0005$ \\
$\mathrm{Cu} u_{70} \mathrm{Fe} e_{30}$ & & & \\
$\mathrm{Fe}-\mathrm{Fe}$ & $2.52 \pm 0.005$ & $2.5 \pm 0.2$ & $0.0066 \pm 0.0008$ \\
$\mathrm{Fe}-\mathrm{Cu}$ & $2.62 \pm 0.01$ & $8.3 \pm 0.4$ & $0.0110 \pm 0.0004$ \\
$\mathrm{Cu}-\mathrm{Fe}$ & $2.62 \pm 0.01$ & $8.0 \pm 0.4$ & $0.0099 \pm 0.0005$ \\
$\mathrm{Cu}-\mathrm{Cu}$ & $2.54 \pm 0.005$ & $2.7 \pm 0.2$ & $0.0089 \pm 0.0005$ \\
\hline \hline
\end{tabular}

in Table I. Also listed in this table are the $S_{0}^{2}$ and $v_{0}$ values which were used to provide the best fit between theory and experiment for the $\mathrm{Cu}$ and $\mathrm{Fe}$ standards. It is noteworthy that the difference between the fitting parameters for the standards and their theoretical values are $\approx 6-7 \%$ in $\mathrm{CN}$ and $\approx 1 \%$ in $r$. Some of these differences can be attributed to the uncertainty related to data collection statistics and the background removal procedures. This uncertainty translates to a $25 \%$ increase in the $\chi^{2}$ fitting parameter. This was determined by fitting the mean \pm one standard deviation with no adjustable parameters using the best-fit parameters which were determined by fitting only the mean. If one systematically steps the values for the best-fit parameters and monitors the change in $\chi^{2}$, one finds that the error bars in Table I double for a $100 \%$ increase in $\chi^{2}$. The errors between the FEFF-calculated and theoretical nearest-neighbor $r$ for fcc $\mathrm{Cu}$ is consistent with the results of Mansour, Wong, and Brizzolara $^{48}$ who found that the FEFF-generated bond distances are often smaller than the theoretical values.

During the fitting of the data from the HEBM samples, the $v_{0}$ and the $S_{0}^{2}$ values determined by the fitting of the standards, were applied directly and a similar approach of fitting refinement was followed. Although the backscattering amplitudes of $\mathrm{Cu}$ and $\mathrm{Fe}$ are very similar, sufficient differences exist in the phases to differentiate the $\mathrm{Cu}$ and $\mathrm{Fe}$ neighbors and allow the determination of the average local composition around the absorbing atoms. The error bars listed on the fitting parameters were determined by fitting the mean of the experimental data plus one standard deviation. The standard deviation of the data was calculated by merging five data scans after the background removal and conversion to $k$-space procedures. When the best-fit parameters for the mean data set were used to fit the mean \pm one standard deviation data, the $\chi^{2}$ parameter increased by $25 \%$. One sees 


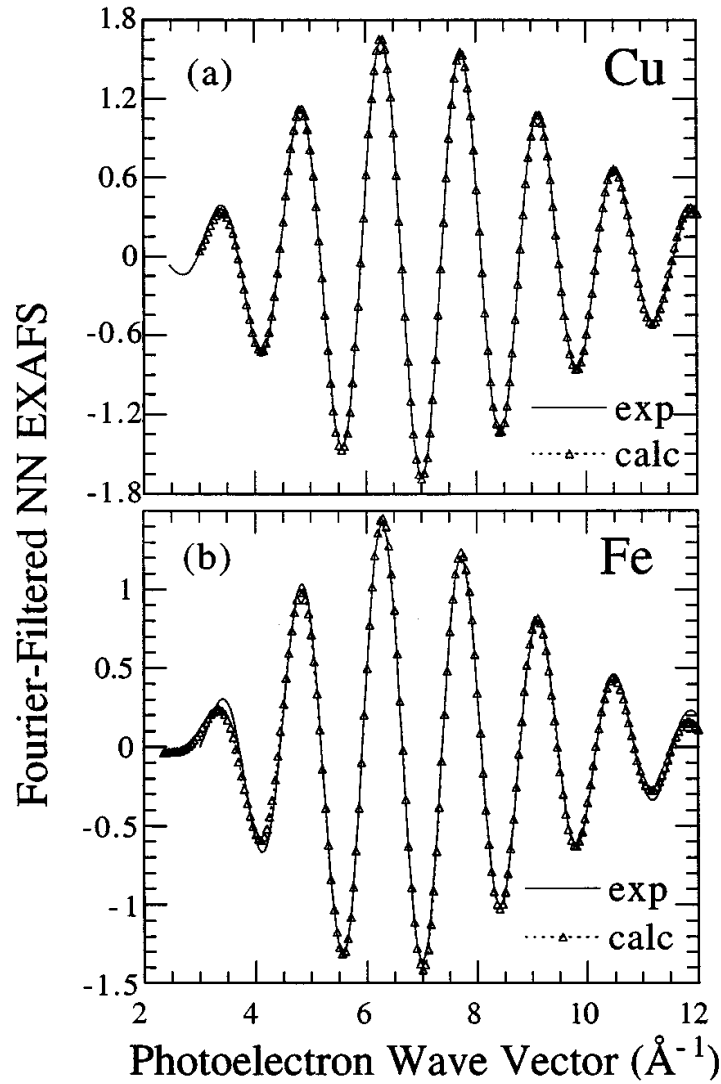

FIG. 10. Fourier-filtered, near-neighbor $\mathrm{Cu}$ (a) and $\mathrm{Fe}$ (b) EXAFS data (solid curves) for the HEBM $\mathrm{Cu}_{70} \mathrm{Fe}_{30}$ sample with the best fit data (dashed curve with symbols) obtained via least-squares fitting of parametrized EXAFS spectra generated using FEFF ver. 3.11 codes (Ref. 44). An $r$-space range of 1-3 $\AA$ was Fourierfiltered from the EXAFS data presented in Fig. 9. The parameters used in these fits are listed in Table I.

that the error bars determined this way are quite small, representing a $0.2-0.3 \%$ deviation from the mean value for $r$, a $5-6 \%$ deviation from the mean value for $\mathrm{CN}$, and $\mathrm{a} \approx 10 \%$ deviation from the mean value for $\sigma^{2}$. From this, one can see that near-neighbor chemistry can be determined using this technique with modest certainty. This allows one to determine the approximate nearest-neighbor chemistry and unambiguously establish if significant amounts of atomic mixing have occurred.

The nearest-neighbor FF $\mathrm{Cu}$ and Fe EXAFS from the $\mathrm{Cu}_{70} \mathrm{Fe}_{30}$ sample and the best fit for both are presented in Figs. 10(a) and 10(b). These data and fits are representative of the $\mathrm{Cu}_{50} \mathrm{Fe}_{50}$ sample. The parameters corresponding to these fits are listed in Table I. For both samples, the best fit resulted from the use of two atomic shells, one of $\mathrm{Fe}$ and the other of $\mathrm{Cu}$, simulating a mixed chemistry in the first coordination sphere. Prior to arriving at this model we had tried to fit the data using a single atomic shell of one or the other atomic species. This lead to relatively poor fits as judged by visual inspection and the value of the $\chi^{2}$ parameter. Attempts to provide a mixed chemistry in the nearest-neighbor environment by using two shells constrained to a single adjustable radial distance was found to greatly improve the fit. However, removing the single-distance constraint resulted in further improvements in the fit with the radial distances of each shell converging to the values listed in Table I. Attempts to simulate fcc Fe clusters within a $\mathrm{Cu}$ fcc matrix by forcing the nearest-neighbor chemistry around $\mathrm{Fe}$ to be enriched with Fe neighbors resulted in a poor fit as judged by the $\chi^{2}$ parameter. As is readily seen in Table I, the fitting of the $\mathrm{Cu}$ EXAFS resulted in parameter values which are consistent and complementary to those of the Fe EXAFS analysis. The ratio of $\mathrm{Cu}$ and $\mathrm{Fe}$ coordination numbers indicates that the first coordination sphere for the $\mathrm{Cu}_{50} \mathrm{Fe}_{50}$ sample consists of a $\mathrm{Cu}_{54} \mathrm{Fe}_{46}$ stoichiometry. This is supported by the independent modeling of both the $\mathrm{Fe}$ and $\mathrm{Cu}$ EXAFS. Energy-dispersive x-ray spectroscopy (EDXS) measurements on this sample indicate that the stoichiometry after milling is $\mathrm{Cu}_{48} \mathrm{Fe}_{52}$. Presumably, the slight increase in the $\mathrm{Fe}$ content is due to contamination from the steel balls and container introduced during the milling. The EXAFS calculated stoichiometry agrees with the EDXS results within the uncertainty of the measurement, and clearly indicates that the first coordination sphere consists of a mixed chemistry near to that measured via EDXS. Similarly, the first coordination sphere for the $\mathrm{Cu}_{70} \mathrm{Fe}_{30}$ sample is measured to have a $\mathrm{Cu}_{75} \mathrm{Fe}_{25}$ stoichiometry. Again, this value is consistent with the nominal values within the uncertainty of the analysis established by the fitting of the mean \pm one standard deviation.

\section{Bond distances and atomic radii}

The measured nearest-neighbor bond distances for like and unlike atom pairs, for both the $\mathrm{Cu}_{50} \mathrm{Fe}_{50}$ and the $\mathrm{Cu}_{70} \mathrm{Fe}_{30}$ samples, are presented in Table I. These data allow the calculation of lattice parameters solely from the results of the EXAFS fitting analysis. Taken together, the resulting EXAFS calculated lattice parameters are $3.649 \pm 0.014 \AA$ and $3.637 \pm 0.010 \AA$, for the $\mathrm{Cu}_{50} \mathrm{Fe}_{50}$ and the $\mathrm{Cu}_{70} \mathrm{Fe}_{30}$ samples, respectively. These values match the values obtained by XRD measurements, $3.641 \pm 0.005 \AA$ and $3.634 \pm 0.003 \AA$, within the uncertainty of the EXAFS and XRD analyses. This agreement indicates that the lattice expansion measured when $\mathrm{Fe}$ is introduced into the $\mathrm{Cu}$ lattice is due to the bond dilation experienced by the unlike atom pairs. It is noteworthy that dilated bonds have been reported in other binary transition-metal solid solutions. Using x-ray diffuse scattering, Ice et al. reported the dilation of $\mathrm{Fe}-\mathrm{Fe}$ bonds in $\mathrm{Fe}-\mathrm{Ni}$ solid solutions ${ }^{49}$ and attribute this effect to an electron kinetic energy of the $\mathrm{Fe}$ atom when it resides on a largevolume, high-spin site. Reinhard et al. ${ }^{50}$ performed similar studies of $\mathrm{Fe}-\mathrm{Cr}$ and found a contraction of the $\mathrm{Fe}-\mathrm{Fe}$ and Cr-Cr distances, while Schonfeld et al. ${ }^{51}$ studied the $\mathrm{Ni}-\mathrm{Cr}$ alloys and found a dilated $\mathrm{Cr}-\mathrm{Ni}$ bond.

The EXAFS calculated nearest-neighbor bond distance for the atom correlations listed in Table I allow the deduction of the atomic radii for $\mathrm{Fe}$ and $\mathrm{Cu}$ in the alloys as well as the standards. These values are listed in Table II with similar values determined from XRD measurements and those calculated by Goldschmidt ${ }^{52}$ and Pauling. ${ }^{53-55}$ The values provided by Goldschmidt derive from an interpolation using Vegard's law and XRD measurements. He calculates atomic radii for different coordination using simple rules of contraction, for example, a $3 \%$ contraction when going from a coordination of 12 to $8,4 \%$ for 12 to 6 , and $12 \%$ when going from 12 to 4 . Although these relationships were derived from empirical studies using salts, they provide a useful approxi- 
TABLE II. Atomic radii calculated from near-neighbor EXAFS modeling compared with values calculated by Goldschmidt and Pauling assuming a coordination of 12 (except where indicated).

\begin{tabular}{lccccc}
\hline \hline Sample & $\begin{array}{c}\text { Atom } \\
\text { correlation }\end{array}$ & $\begin{array}{c}\text { EXAFS } \\
(\AA)\end{array}$ & $\begin{array}{c}\text { XRD } \\
(\AA)\end{array}$ & $\begin{array}{c}\text { Goldschmidt } \\
(\AA)\end{array}$ & $\begin{array}{c}\text { Pauling } \\
(\AA)\end{array}$ \\
\hline Fe foil & $\mathrm{Fe}-\mathrm{Fe}$ & $1.245 \pm 0.0025$ & 1.241 & $1.24^{\mathrm{a}}$ & \\
$\mathrm{Cu}$ foil & $\mathrm{Cu}-\mathrm{Cu}$ & $1.270 \pm 0.0025$ & 1.278 & 1.28 & 1.276 \\
$\mathrm{Cu}_{50} \mathrm{Fe}_{50}$ & $\mathrm{Fe}-\mathrm{Fe}$ & $1.265 \pm 0.0025$ & & 1.27 & 1.26 \\
$\mathrm{Cu}_{50} \mathrm{Fe}_{50}$ & $\mathrm{Cu}-\mathrm{Cu}$ & $1.275 \pm 0.0025$ & & 1.28 & 1.276 \\
$\mathrm{Cu}_{50} \mathrm{Fe}_{50}$ & $\mathrm{Fe}-\mathrm{Cu}$ & $1.3125 \pm 0.005$ & $1.2873 \pm 0.0018^{\mathrm{b}}$ & & \\
$\mathrm{Cu}_{70} \mathrm{Fe}_{30}$ & $\mathrm{Fe}-\mathrm{Fe}$ & $1.260 \pm 0.0025$ & & 1.27 & 1.26 \\
$\mathrm{Cu}_{70} \mathrm{Fe}_{30}$ & $\mathrm{Cu}-\mathrm{Cu}$ & $1.270 \pm 0.0025$ & & 1.28 & 1.276 \\
$\mathrm{Cu}_{70} \mathrm{Fe}_{30}$ & $\mathrm{Fe}-\mathrm{Cu}$ & $1.310 \pm 0.005$ & $1.2848 \pm 0.0011^{\mathrm{b}}$ & & \\
\hline \hline
\end{tabular}

${ }^{\mathrm{a}}$ Calculated assuming a coordination of 8 .

${ }^{\mathrm{b}}$ This represents the average atomic radii determined from XRD, no distinction is made concerning the individual atom pair correlations.

mation of atomic radii in metallic alloys. Pauling's values are based upon his postulation that the interatomic forces in metals can be modeled as resonating covalent bonds among the available atomic positions. He calculates the atomic radii using a relationship which accounts for both the number of available bonds, determined by valence, and the radius of a single resonant bond. ${ }^{54-56}$

In Table II one sees that the EXAFS-calculated atomic radii for the $\mathrm{Cu}$ and $\mathrm{Fe}$ standards are in good agreement with those measured by XRD and those calculated by both Goldschmidt and Pauling. Although there are statistically significant differences, that likely stem from the limitations of the EXAFS simulation codes, as a whole these differences are small and the agreement is excellent. In contrast, the average atomic radii calculated by EXAFS for the unlike atom pair correlations are very much larger than the values calculated

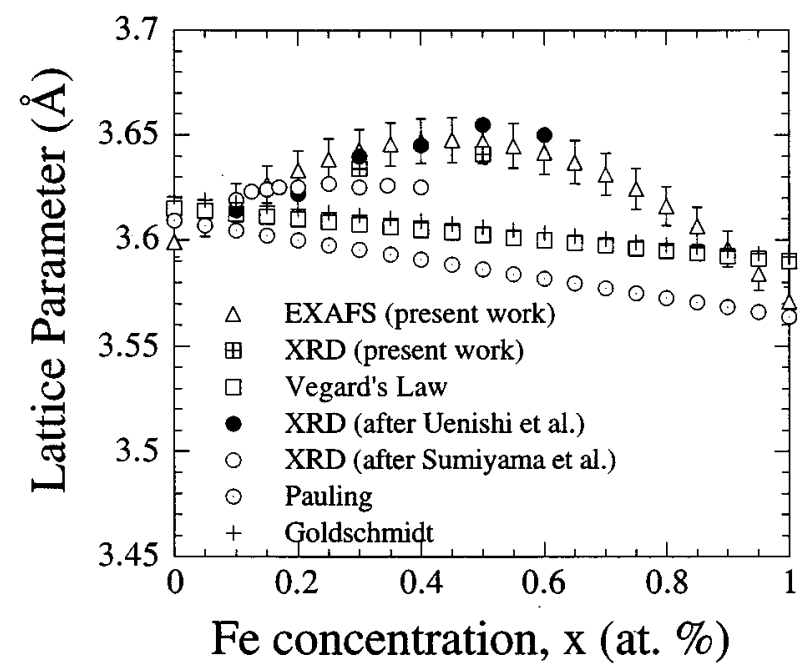

FIG. 11. Plot of lattice parameter versus Fe concentration in $\mathrm{Cu}-\mathrm{Fe}$ alloys. Values calculated from XRD measurements for the samples studied here are plotted with values calculated using the atomic radii of Goldschmidt and Pauling and values calculated using the atomic radii measured via the EXAFS analysis presented here. Solid line represents Vegard's law. The circles appearing at $0 \leqslant x \leqslant 0.40$ correspond to values measured for vapor-quenched $\mathrm{Cu}-\mathrm{Fe}$ after Sumiyama, Yoshitake, and Nakamura (Ref. 4), and the solid circles appearing at $0 \leqslant x \leqslant 0.60$ correspond to values measured for HEBM Cu-Fe after Uenishi et al. (Ref. 26). by Goldschmidt and Pauling, by 2.75 and $3.33 \%$, respectively.

Presented in Fig. 11 are the lattice parameters of $\mathrm{Cu}-\mathrm{Fe}$ alloys calculated via the EXAFS fitting results, measured by $\mathrm{XRD}$, calculated using the atomic radii of Goldschmidt and Pauling, and predicted by Vegard's law. As one would expect, the values calculated using the sum of the Goldschmidt radii plot very near to those predicted by Vegard's law. In contrast, values calculated using the sum of the Pauling radii fit closely to Vegard's law for low Fe concentrations but deviate for high Fe concentrations. The two XRD-measured lattice parameters determined for the HEBM samples studied here are shown to deviate positively from Vegard's law. These values are in very good agreement with other values measured for HEBM Cu-Fe samples, ${ }^{26}$ but are larger than values measured for vapor-quenched $\mathrm{Cu}-\mathrm{Fe}$ films. ${ }^{4}$ The values calculated using the discrete bond distances determined by the EXAFS modeling plot on a parabola which deviates positively from Vegard's law. These later values, with error bars, are shown to encompass the XRD-measured lattice parameters for the two samples studied here and the values of Uenishi et al. for other HEBM Cu-Fe samples. This is strong evidence that the EXAFS fitting results represent the real physical state of the sample.

\section{E. Origins of the $\mathrm{Cu}-\mathrm{Fe}$ bond dilation}

Figure 12 is schematic representation of an arrangement of $\mathrm{Cu}$ and $\mathrm{Fe}$ atoms which is consistent with the EXAFS modeling results presented in Tables I and II and Fig. 11. In this figure, the solid-line circles represent atom sites on an undistorted fcc lattice while the hashed circles represent $\mathrm{Fe}$ and $\mathrm{Cu}$ atoms slightly displaced from these sites. (The dashed-line circles represent sites which lie on planes beneath the surface layers.) The $\mathrm{Cu}$ and $\mathrm{Fe}$ atoms are shown in this figure to be displaced from the lattice sites, where like neighbors are closer than the $\left(\sqrt{2} a_{0}\right) / 2\left(a_{0}=\right.$ lattice parameter $)$ value for the nearest-neighbor distance in the fcc structure, and the unlike neighbors are displaced to greater distances. The undistorted fcc lattice is what would be measured by XRD.

We propose that the bond dilation of the unlike atom pairs is the consequence of a wave-function interaction. The Fe-Fe interaction is strong and determined by the hybridization of the $d$-shell electron wave functions, whereas the $\mathrm{Cu}-\mathrm{Cu}$ 


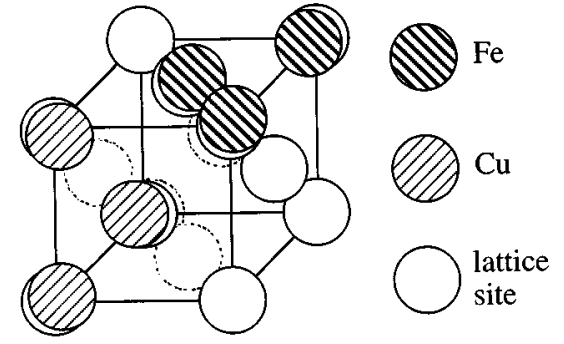

FIG. 12. Schematic representation of atom arrangements which are consistent with the EXAFS modeling results (the drawing is not drawn to relative scale). The solid circles represent lattice sites in an ideal fcc structure with dashed circles representing the background plane of atoms. The hashed circles are the atoms displaced from the ideal lattice indicating the dilation of the unlike atom bonds and the affinity for like pairing. For clarity not all lattice sites are filled.

neighbors experience strong interaction by the overlap of the $s$-shell electron wave functions and the hybridization of the inner $p$ and $d$ shells. However, the dilated bonds measured between $\mathrm{Cu}$ and $\mathrm{Fe}$ indicate either a very weak interaction or a repulsion exist between unlike neighbors. Pearson suggests that bond dilation observed in solid solutions may occur when repulsive forces are generated by the overlap of the tails of the electron wave functions. ${ }^{57}$ However, because the magnetic moment of Fe is largely unaffected by the introduction of $\mathrm{Cu}$ there is little or no hybridization of the $\mathrm{Fe} d$ shell by the $\mathrm{Cu} 4 s, 3 p$ or $3 d$ electrons. We propose that the strong interaction between the like atom pairs provide $\mathrm{Cou}-$ lombic forces which establish geometrical limitations which prohibit the $\mathrm{Fe}-\mathrm{Cu}$ pairs from coming any closer than the measured distances.

\section{CONCLUSIONS}

We have performed $\mathrm{x}$-ray diffraction (XRD) and extended $\mathrm{X}$-ray-absorption fine structure (EXAFS) measurements, including EXAFS near-neighbor modeling analyses on $\mathrm{Cu}_{50} \mathrm{Fe}_{50}$ and $\mathrm{Cu}_{70} \mathrm{Fe}_{30}$ high-energy ball-milled (HEBM) samples, to investigate the effects of HEBM on the local structure and chemistry of samples having a positive heat of mixing.

(1) X-ray-diffraction measurements for both HEBM samples illustrate only one family of fcc diffraction peaks suggesting that the $\mathrm{Fe}$ and $\mathrm{Cu}$ coexists in a single fcc phase. Lattice parameters of 3.641 and $3.634 \AA$ were calculated for the $\mathrm{Cu}_{50} \mathrm{Fe}_{50}$ and $\mathrm{Cu}_{70} \mathrm{Fe}_{30}$ samples, respectively. These values are significantly greater than that of fcc $\mathrm{Cu}, 3.615 \AA$, representing a 2.1 and $1.6 \%$ increase in unit-cell volume, respectively, and are larger still compared with the values predicted by Vegard's law (3.6025 $\AA$ for $\mathrm{Cu}_{50} \mathrm{Fe}_{50}$, a change of $3.24 \%$ in volume, and $3.6075 \AA$ for $\mathrm{Cu}_{70} \mathrm{Fe}_{30}$, a change of $2.22 \%$ in volume). Lattice expansions of similar magnitude have been measured in other HEBM Cu-Fe samples. ${ }^{26}$ Vapor-quenched $\mathrm{Cu}-\mathrm{Fe}$ films have been measured to have much smaller lattice expansions. ${ }^{4,5}$

(2) Fourier-transformed $\mathrm{Fe}$ and $\mathrm{Cu}$ EXAFS data illustrate that both the $\mathrm{Fe}$ and $\mathrm{Cu}$ atoms reside in a close-packed arrangement similar to that of fcc $\mathrm{Cu}$. A shift in the nearestneighbor peak position to higher $r$ values in the HEBM samples compared with that of the fcc $\mathrm{Cu}$ standard, suggests that the lattice positions for $\mathrm{Cu}$ and $\mathrm{Fe}$ are slightly expanded with respect to $\mathrm{Cu}$. This is in qualitative agreement with the XRD-measured lattice expansion.

(3) Fitting of the nearest-neighbor peak region in the Fourier-transformed EXAFS data was performed with parametrized theoretical EXAFS data generated via the FEFF 3.11 codes. $^{44}$ Best fits to the first coordination sphere were obtained using two shells of atoms, one of $\mathrm{Cu}$ and the other of $\mathrm{Fe}$, displaced from one another. Results indicate that the nearest-neighbor chemistry of the HEBM samples are very close to that of the nominal stoichiometry of the starting materials indicating that atomic-level mixing has occurred and a supersaturated-solid-solution exist.

(4) From the EXAFS fitting analysis the nearest-neighbor bond distances for like and unlike neighbors were deduced. Bond distances between like neighbors are very close to those one would expect for elemental fcc phases of these elements. However, the unlike atom pairs are calculated to be dilated to a distance of $2.625 \pm 0.01 \AA$. Lattice parameters calculated using the bond distances determined from EXAFS are found to be in excellent agreement with those measured via XRD.

(5) The atomic radii deduced from EXAFS modeling are compared with those determined from XRD measurements and those calculated using Goldschmidt and Pauling radii. The EXAFS radii corresponding to like atom pairs are in excellent agreement with the values from XRD, Goldschmidt and Pauling. However, the unlike atom pair bond distances are much greater than the sum of these radii. A qualitative model is proposed that attributes this effect to a Coulombic displacement of unlike pairs caused by the affinity for like pair bonding. This affinity originates from the hybridization of the valence electron wave functions, acts to define a minimum interatomic distance between like pairs in the fcc structure, and displaces the unlike pairs, which have a lower binding energy, away from one another.

These results establish that atomic-level mixing has indeed occurred around $\mathrm{Fe}$ and $\mathrm{Cu}$ sites in these HEBM $\mathrm{Cu}-\mathrm{Fe}$ samples. Although researchers have long assumed that HEBM facilitates the formation of alloys through solid-state transformations, often using the disappearance of the Bragg reflections in diffraction experiments as evidence, this represents direct experimental evidence obtained via an elementspecific, local probe having sufficient sensitivity to investigate the chemistry of the first coordination sphere.

\section{ACKNOWLEDGMENTS}

The authors express their appreciation to Dr. Kristl Hathaway (NRL) for valuable discussions concerning the magnetic and electronic properties of the $\mathrm{Fe}-\mathrm{Cu}$ and $\mathrm{Fe} / \mathrm{Cu}$ systems, and to Professor J. J. Rehr and associates (University of Washington) for providing us with the theoretical EXAFS simulation (i.e., FEFF) codes used here. This research was carried out in part at the National Synchrotron Light Source (Brookhaven National Laboratories, Upton, New York), which is sponsored by the U.S. Department of Energy. In addition, some of the samples included in this research were processed and characterized with support from the Spanish CICYT through projects Mat. 92-0491 and Mat. 92-0404. A.H. acknowledges support to the BBV Foundation and K.M.K. acknowledges support of the National Research Council during the time of this research. 
${ }^{1}$ J. Q. Xiao, J. S. Jiang, and C. L. Chien, Phys. Rev. Lett. 68, 3749 (1992).

${ }^{2}$ A. E. Berkowitz, J. R. Mitchel, M. J. Carey, A. P. Young, S. Zhang, F. E. Spada, F. T. Parker, A. Hutten, and G. Thomas, Phys. Rev. Lett. 68, 3745 (1992).

${ }^{3}$ M. Hansen, in Constitution of Binary Alloys, edited by M. Hansen (McGraw-Hill, New York, 1958), p. 580.

${ }^{4}$ K. Sumiyama, T. Yoshitake, and Y. Nakumura, J. Phys. Soc. Jpn. 53, 3160 (1984).

${ }^{5}$ C. L. Chien, S. H. Liou, D. Kofalt, W. Yu, T. Egami, and T. R. McGuire, Phys. Rev. B 33, 3247 (1986).

${ }^{6}$ A. Y. Yermakov, Y. Y. Yurchikov, and V. A. Varinov, Phys. Met. Metallogr. 52, 50 (1981).

${ }^{7}$ C. C. Koch, O. B. Gavin, C. G. Mackamey, and J. O. Scarbrough, Appl. Phys. Lett. 43, 1017 (1983).

${ }^{8}$ T. Nasu, C. C. Koch, K. Nagaoka, N. Itoh, M. Sakurai, and K. Suzuki, Mater. Sci. Eng. A 134, 1385 (1991).

${ }^{9}$ H. Miura, S. Isa, and K. Omuro, Jpn. J. Appl. Phys. 29, L339 (1990).

${ }^{10}$ T. Nasu, K. Nagaoka, N. Itoh, and K. Suzuki, J. Non-Cryst. Solids 122, 216 (1990).

${ }^{11}$ E. Gaffet and M. Harmelin, J. Less Common Met. 157, 201 (1990).

${ }^{12}$ A. R. Yavari and P. J. Desre, Phys. Rev. Lett. 65, 2571 (1990).

${ }^{13}$ R. Shulz, M. Trudeau, and J. Y. Huot, Phys. Rev. Lett. 62, 2849 (1989).

${ }^{14}$ M. L. Trudeau, R. Shulz, D. Dussault, and A. V. Neste, Phys. Rev. Lett. 64, 99 (1990).

${ }^{15}$ A. R. Yavari, P. J. Desre, and T. Benameur, Phys. Rev. Lett. 68, 2235 (1992).

${ }^{16}$ P. H. Shingu, K. N. Ishihara, K. Uenishi, J. Koyama, B. Huang, and S. Nasu, in Solid State Powder Processing, edited by A. H. Clauer and J. J. de Barbadillo (Minerals, Metals and Materials Society, Warrandale, PA, 1990), pp. 21-24.

${ }^{17}$ J. Kuyama, H. Inui, S. Imaoka, K. N. Ishihara, and P. Shingu, Jpn. J. Appl. Phys. 30, L854 (1991).

${ }^{18}$ K. Uenishi, K. F. Kobayashi, K. N. Ishihara, and P. H. Shingu, Mater. Sci. Eng. A 134, 1342 (1991).

${ }^{19}$ V. G. Harris, W. T. Elam, B. N. Das, and N. C. Koon, National Synchrotron Light Source Report No. BNL52415, B-193 (1993).

${ }^{20}$ P. Crespo, A. Hernando, A. G. Escorial, K. M. Kemner, and V. G. Harris, J. Appl. Phys. 76, 6322 (1994).

${ }^{21}$ P. J. Schilling, J.-H. He, J. Cheng, and E. Ma, Appl. Phys. Lett. 68, 767 (1996).

${ }^{22}$ P. S. Jilman and J. S. Benjamin, Annu. Rev. Mater. Sci. 13, 279 (1983)

${ }^{23}$ R. B. Schartz, R. R. Petrich, and C. K. Saw, J. Non-Cryst. Solids 76, 281 (1985).

${ }^{24}$ A. Hernando, P. Crespo, A. G. Escorial, and J. M. Barandiaran, Phys. Rev. Lett. 70, 3521 (1993).

${ }^{25}$ P. Crespo, A. Hernando, A. R. Yavari, O. Drbohlav, A. G. Escorial, J. M. Barandiaran, and I. Orue, Phys. Rev. B 48, 7134 (1993).

${ }^{26}$ K. Uenishi, K. F. Kobayashi, S. Nasu, H. Hatano, K. N. Ishihara, and P. H. Shingu, Z. Metallkd. 83, 132 (1992).
${ }^{27}$ R. M. Bozorth, Ferromagnetism (Van Nostrand, Princeton, NJ, 1978).

${ }^{28}$ J. T. Norton, Trans. Metall. Soc. AIME 116, 386 (1935).

${ }^{29}$ L. S. Darken and H. A. Wriedt, Trans. Metall. Soc. AIME 218, 30 (1960).

${ }^{30}$ J. W. Klement, Trans. Metall. Soc. AIME 233, 1180 (1965).

${ }^{31}$ E. F. Kneller, J. Appl. Phys. 35, 2210 (1964).

${ }^{32}$ T. Ambrose, A. Gavrin, and C. L. Chien, J. Magn. Magn. Mater. 124, 15 (1993).

${ }^{33}$ P. H. Shingu, K. N. Ishihara, K. Uenishi, J. Kuyama, B. Huang, and S. Nasu, in Solid State Powder Processing (Ref. 16), p. 21.

${ }^{34}$ L. Pauling, in Theory of Alloy Phases (American Society for Metals, Cleveland, OH, 1956), p. 220.

${ }^{35}$ E. C. Stoner, Philos. Mag. 15, 1018 (1933).

${ }^{36}$ B. Cordts, D. M. Pease, and L. V. Azaroff, Phys. Rev. B 22, 4692 (1980).

${ }^{37}$ D. M. Pease, G. H. Hayes, M. Choi, J. I. Budnick, W. A. Hines, R. Hesagawa, and S. M. Heald, J. Non-Cryst. Solids 61-62, 1359 (1984).

${ }^{38}$ M. Munoz, P. J. Durham, and B. L. Gyorffy, J. Phys. F 12, 1497 (1982).

${ }^{39}$ V. L. Moruzzi, J. F. Janak, and A. R. Williams, Calculated Electronic Properties of Metals (Pergamon, New York, 1978).

${ }^{40}$ C. L. Fu and A. J. Freeman, Phys. Rev. B 35, 925 (1987).

${ }^{41}$ E. Wimmer, H. Krakauer, M. Weinert, and A. J. Freeman, Phys. Rev. B 24, 864 (1981).

${ }^{42}$ Brand names are used here to be specific. Their use is not to be interpreted as an endorsement by the Federal government.

${ }^{43}$ D. E. Sayers and B. A. Bunker, in X-ray Absorption: Principles, Applications, Techniques of EXAFS, SEXAFS and XANES, edited by D. C. Koningsberger and R. Prins (Wiley, New York, 1988), p. 211.

${ }^{44}$ J. J. Rehr, J. M. d. Leon, S. I. Zabinsky, and R. C. Albers, J. Am. Chem. Soc. 113, 5135 (1991).

${ }^{45}$ E. Stern, D. Sayers, and F. Lytle, in X-ray Absorption Fine Structure, edited by S. S. Hasnain (Harwood, Chichester, UK, 1991), p. 751.

${ }^{46}$ P. H. Duwez, R. H. Willens, and W. Klement, J. Appl. Phys. 31, 1136 (1960).

${ }^{47}$ J. B. Newkirk, Trans. Metall. Soc. AIME 138, 1214 (1957).

${ }^{48}$ A. N. Mansour, C.-P. Wong, and R. A. Brizzolara, Phys. Rev. B 50, 12401 (1994).

${ }^{49}$ G. E. Ice, C. J. Sparks, A. Habenschuss, and L. B. Shaffer, Phys. Rev. Lett. 68, 863 (1992).

${ }^{50}$ L. Reinhard, J. L. Robertson, S. C. Moss, G. E. Ice, P. Zschick, and C. J. Sparks, Phys. Rev. B 45, 2662 (1992).

${ }^{51}$ B. Schonfeld, G. E. Ice, C. J. Sparks, H.-G. Haubold, W. Scheika, and L. B. Shaffer, Phys. Rev. B 183, 79 (1994).

${ }^{52}$ V. M. Goldschmidt, Z. Phys. Chem. (Leipzig) 133, 397 (1928).

${ }^{53}$ L. Pauling, The Nature of the Chemical Bond (Cornell University Press, Ithaca, 1940).

${ }^{54}$ L. Pauling, J. Am. Chem. Soc. 69, 542 (1947).

${ }^{55}$ L. Pauling, Proc. R. Soc. London 196A, 343 (1949).

${ }^{56}$ L. Pauling, Phys. Rev. 54, 899 (1938).

${ }^{57}$ W. B. Pearson, in The Chemical Structure of Solids, Vol. I, edited by N. B. Hannay (Plenum, New York, 1976), Vol. 1, p. 115. 